\title{
Translation as Reverse Engineering, Phase 1: Converting The Words in A Text Into Pictures in The Mind
}

\author{
Roger T. Bell \\ Universitas Sumatera Utara \\ \{rogertbell@gmail.com\} \\ Linguistics Department, Universitas Sumatera Utara, Medan, Indonesia
}

\begin{abstract}
It has long been recognised that translation is a two phase input-output process - reading (deconstructing) and writing (reconstructing) - in which the "source text" is, in some way, reformulated as the "target text": the translation. The problem lies in the "somehow" and it is the purpose of this paper to suggest a plausible explanation of the process and outline a novel approach (Reverse Engineering) - a reformulation of the well-established technique of "close reading" - which is offered to those who are reading with the intention of creating a translation (mono- or bi-lingually) and need to bring their semi-automatic skills to the level of conscious that will allow them share what they have discovered about the text with others, either through discussion or translation. This paper deals with Phase one and paves the way for the next: Phase 2 (translating).
\end{abstract}

Keywords: deconstruction, meaning, reading. Reverse Engineering.

\section{Introduction}

Teasing apart the notions of "reading", "writing" and "translation" is no simple task. Common sense definitions would be along the lines of "reading is making sense of a written text", "writing is making a permanent record of ideas" and "translation is converting the content of a text in one language into a text in another". [1] Steiner G, however, would argue that all linguistic communication is translation and [2] Jakobson R, would go further, arguing that since language is just one of many systems of signs (semiotic systems) used for communication, we should recognise three types of translation: 1. intralinguistic (or rewording) "an interpretation of verbal signs by means of other signs of the same language", e.g. a rewriting: summary, paraphrase etc. 2. interlinguistic (or translation proper) e.g. converting an English text into one in Bahasa Indonesia and 3. intersemiotic (or transmutation) "an interpretation of verbal signs by means of signs of non-verbal sign systems" e.g. converting the written text of Romeo and Juliet (Shakespeare) into a ballet (Prokofiev).

Naturally, too, not all texts are realised in writing. The same message can, as in the case of figure 1 below, be equally or better sent in a different non-language system such as that use for international safety signs. [3] . 


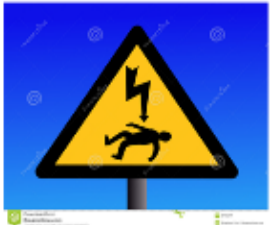

Figure 1: Danger; high voltage.

"Hybrid" texts in which two or more systems are used are also far from uncommon e.g. as in Figure 2 below, where, even if the reader cannot understand the language content, (s)he can get the message conveyed by the international sign.

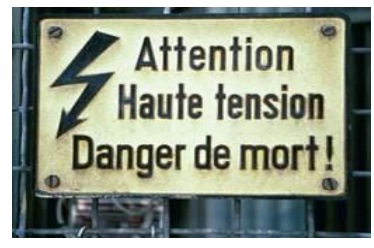

Figure 2: Danger; high voltage

Given this, it does not seem unreasonable to use "Translation" in the title of this paper and its sequel, even though each only deals with half of the process.

\subsection{Reading}

Reading is a matter of problem-solving which, like all problems, entails deciding on a broad approach consisting of an overall strategy and, within that, a number of appropriate tactics: typically, bottom-up processing of available information combined with top-down inferencing of more precise information based on that [4] Brown G, Yule G.

An example might be the resolution of a riddle such as the following: "What 4-letter English word can be written forward, backward or upside down, and can still be read from left to right?"

We might select the strategy of working our way through the alphabet, the bottom-up tactic of looking for vowels that can occur between pairs of consonants, and the top-down tactic of testing each until, eventually, we arrive at a list of six plausible answers: "deed", "peep", "boob", "noon", "poop", "toot", plus "naan", if we are willing to accept Indian flat bread, and "beeb", if we accept the UK abbreviation for the BBC: a process of failed tests and sudden breakthroughs. 


\subsection{Meaning}

While we will probably readily agree that reading consists of "making sense" of a text, we might find it harder to accept that this certainly does not mean finding meaning in the words of the text but through them.

Words have no inherent meaning and, in any case, a word without a context would be totally devoid of meaning: no more than "black marks on paper". What, for example, does "tak" mean? For a speaker of Bahasa Indonesia or Bahasa Malaysia, it will indicate negation ("not"), for a speaker of Czech or Polish, the opposite, confirmation ("so") and, for a speaker of a Scandinavian language, Danish "tak", Norwegian "takk", and Swedish "tack", all express gratitude ("thank you") and, spelled like the Swedish "thank you", for English speakers, a small flat-headed nail!

Words are, in fact, like light switches which "illuminate" existing meanings stored in the mind of the individual or, to slightly shift the analogy, "hyper-links" in the brain that take us to further words and meanings that are located in two interlinked long-term memory systems: conceptual - including the rules of language (both formal and functional) and those of mathematics or chemistry etc.... (symbols) - and episodic: memories of "what happened to me" (pictures in the mind) [5] Bell, RT.

Given this, the ancient epigram is clearly in need of updating and expansion: "A word is worth 1000 pictures, each of which is worth 1000 words and pictures, each of which..."

As might be expected, there are links between the two e.g. for me the word "Victory" is inextricably linked to the picture of my mother and me in Trafalgar Square in London on $8^{\text {th }}$ May 1945, listening to Churchill's speech declaring that WW2 was over and, at the same time, watching (somewhat disapprovingly) a sailor climb up a lamp post!

Also, as [6] Diekman, J.R, neatly puts it "Meaning is in people, not in words" and, since meanings arise from the unique life experiences of individuals, the words that act as triggers for meanings will, of necessity, call up different meanings. For example, the meaning of AIR depends entirely on user experience: in the Malay-speaking world they fill radiators with it; in the English-speaking world they inflate tyres! It is all, as figure 3 below illustrates, a matter of experience and perspective. 


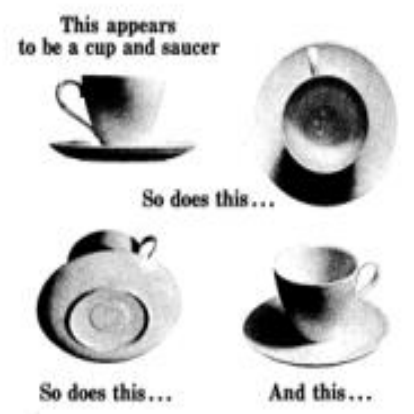

Figure 3: Perspective

If we follow this line of argument to its logical conclusion, we end up recognising that the text is a system of potential meanings which can be realised as many actual meanings in the minds of readers and, since these will be the unique creation of individuals, they will be provisional and changing as the creator tests potential interpretations and acquires additional relevant information.

In short, the search for the meaning of a text is a chimera.

\subsection{Deconstruction ${ }^{1}$}

What happens in the course of reading, is that the original actual text is deconstructed and converted in the mind of each reader into a virtual text: an abstract, mental representation that contains everything (s)he has derived from the analysis of the original. The process is one of phase change from static artefact to a mobile entity comparable to the defrosting of solid ice into fluid water or boiling water into amorphous vapour (see [7] Sayers, Peden).

In practical terms, it seems inevitable that all readers must use some kind of analytical technique for making sense of texts though most will not do so consciously. They will pay little attention to the formal characteristics of the text when reading for information or pleasure and will have no need for the kind of procedure being proposed in this paper.

In contrast with the general reader, those in professions which are intimately connected with language, such as Academia, Advertising, the Law, and the Press, and anyone reading with the intention of later creating a text that is to be shared with others, either through discussion or translation (in the broadest sense), must commit time and effort to the careful reading of the text which, it is suggested here, can be enhanced by the adoption and application of the principles and techniques of Reverse Engineering

\footnotetext{
1 The term is used here in the limited sense of an essentially sociolinguistic analysis of texts in the context of modelling the process of translation. It does not aim to go further into the wider areas treated by such writers as Derrida (see [9] Lawlor, L.) and others e.g. [10] Fairclough, NL.
} 


\subsection{Translation as Reverse Engineering}

The inspiration for Reverse Engineering comes from Newton's famous 1666 experiment in which white light was refracted through a prism into the colours of the rainbow, and its application to translation from [8] Darwish, A.

The process, which is carried out in three phases, consists of taking something apart and analysing its workings in detail, usually with the intention of constructing a new device which fulfils the same function but is not a copy, since it differs from the original in form and, to some degree, in content.

\section{Phases}

1. Identifying the original system's components and their interrelationships

2. Creating an abstract model of the original

3. Producing a physical representation the model. [11]

The equivalent phases applied to translation would be:

1. Identifying the source text's components and their interrelationships (accessing the textual interface),

2. Creating an abstract, mental representation of it (a virtual text): and

3. Producing the physical representation of the virtual text (the translation: an actual text).

The whole process is 1) non-linear (not unidirectional) and there is no order in which the steps must be taken ${ }^{2}$ other than the necessity to begin with the text), 2) cascaded (a step need not be completed before moving on to another) and 3) interactive (checking, backtracking and revision are the norm rather than the exception) [5] Bell 7-8 and 220.

Stage 1 is concerned with accessing the textual interface in order to make a careful study of what [12] Searle, J calls "brute facts": 1. how it is presented and 2. its lexico-grammatical structure. These provide objective, immediately observable facts that can be identified by reference to already stored meanings in the mind of any reader who is literate in the language(s) used in the text (column A in Table 1 below) and also suggests links from surface to deep meaning available in Stage 2.

Stage 2 is concerned with following the links suggested by Stage 1 to infer what [12] Searle, J calls "social facts": subjective, hidden facts that can be identified by reference to already stored meanings in the mind of the individual reader (column B in Table 1 below) located (stored in long-term memory) in four interlinked layers of information: 1. contextual, 2. cultural, 3. intentional, and 4. intertextual $\quad$ [8] Darwish, A. ${ }^{3}$

2 The layers are listed in alphabetical order not order of access.

3 The next section provides a detailed description of the contents of each layer and proposes ways of accessing it. 
Table 1: Meaning

\begin{tabular}{|l|l|}
\hline \multicolumn{2}{|c|}{ Meaning } \\
\hline A & B \\
\hline surface & deep \\
\hline overt & covert \\
\hline explicit & implicit \\
\hline context-free & context-sensitive \\
\hline primary & secondary \\
\hline literal & metaphorical \\
\hline denotative & connotative \\
\hline semantic sense & communicative value \\
\hline
\end{tabular}

The reader moves backwards and forwards, as (s)he chooses, along the ten available paths between the text and the layers and between the layers themselves, making decisions on the spot, observing or inferring something that triggers moves to other levels where top-down processing is employed to infer something from what has been observed and then, maybe, going back to the text to check the actual facts before moving on again to another level and revising as (s)he amasses new information from all five sources, tracing different decision chains and producing different interpretations, and making increasingly sophisticated sense of the text and only coming to an end when the (s)he is sufficiently satisfied with the unique "rich picture" [13] Checkland, P. (s)he has created and is ready, if (s)he wishes, to set about the reconstruction phase on the basis of this particular provisional reading (the fundamental part of the process, without the feedback loops, is shown in figure 4 below.
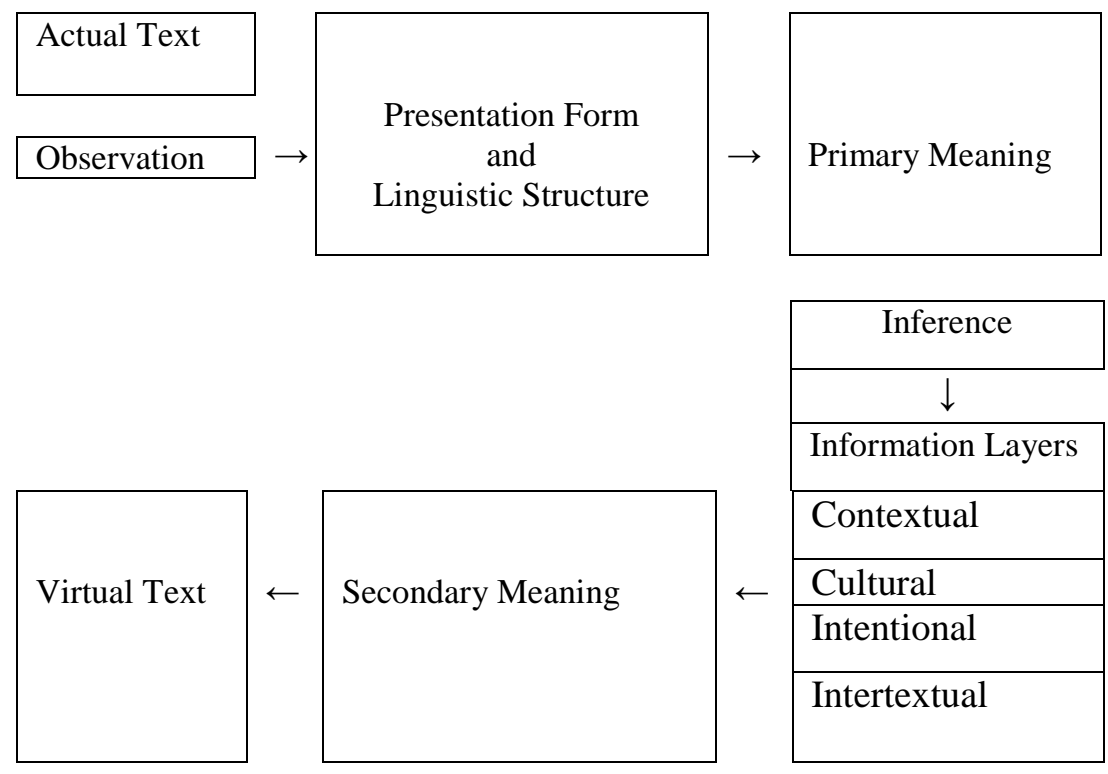

Figure 4:Translation as Reverse Engineering Phase 1: deconstruction 
Comment A reader who was only able to carry out Stage 1 would be faced by a major problem. Nothing but literal meanings are revealed by the analysis of the actual text. Admittedly, the lexis will give a general idea of how accessible the text is and the relative complexity of the syntax its readability but, without access to the four levels, metaphorical meanings would remain concealed. So much would be uncertain: the text's temporal and/or location, and/or the characteristics of those who participated in its creation, its text type and cultural orientation, the writer's intention and expectations for its effect on readers.

There is no direct correlation between surface syntactic structure and deep semantic sense e.g. "Come round on Sunday" is an imperative but can also count as [12] Searle, J. an Order; a Request; an Instruction; a Suggestion; an Invitation [5] Bell.

A text is, unquestionably, a tangible, physical artefact ${ }^{4}$ created by a human being. It is also, and more significantly, a cultural ${ }^{5}$ artefact, and the process of "unpacking" its meaning rather resembles how field archaeology is conducted. First of all, a site is chosen - usually on the basis of existing historical value - and an area marked out for excavation where objects begin to be found on the surface which are catalogued in terms of their location and general physical characteristics and assigned a provisional identification. Next a trench is dug which increases in size as digging vertically and horizontally reveals new layers containing new finds which are catalogued and, later, studied closely to discover what they are and, most importantly, what they are for.

However, there is an important distinction to be made between the archaeological site which often provides a record of human activity but the text is always a record of human activity: a communicative event - a series of communicative acts - performed by members of a speech community within a particular culture.

One implication of this is, given the personal (as well as social) nature of such events, that there is no such thing as a culture-free action, since all actions will tend to confirm or disrupt the cultural status quo. Access to new information is potentially disruptive, perhaps dramatically, as in the case of the following examples which were, to a great extent, instrumental in the ending of the Medieval World and, through the Renaissance and Reformation, the rise of democracy, the Industrial, Technological and Digital Revolutions, the creation of the "global village" in which we now live.

The two interlinked examples are the 1. translations by scholars of the Andalusian Caliphate in Spain (12 ${ }^{\text {th }}-13$ th CE), of Greek and Latin texts that had been "lost" to Western Europe for a millennium [14] Baker, M. 1998103 and 2. the invention of the moveable type printing press, in 1450 which increased availability of cheap books and promoted rising levels of literacy, it facilitated [15] Littlejohn, A.

Nonetheless, it seems likely that few acts are intentionally disruptive. It is hard to imagine how a society could operate at all without an agreement, at least tacit, amongst its members to co-operate in the sharing of information since, as [16] Trompenaars and Hampden-Turner 2001.87 say, 
"People everywhere are as one in having to face up to the same challenges of existence... dilemmas in relationships with people, in relationship to time [and] in relationship between people and the natural environment"

The Co-operative Principle It is hard to imagine how a society could operate without a agreement, at least tacit, amongst its members to co-operate in the sharing of information.

The sender in a communicative event has a responsibility for the difficult task of attempting to ensure that the messages (s)he sends are comprehensible: sufficiently informative, true, relevant and clear to satisfy the receiver's needs. These responsibilities have been formulated in the Co-operative Principle (and its four component maxims) by [17] Grice, H. and are set out in table 2 below. The receiver also has a reciprocal responsibility to the sender to co-operate in making the exchange a success by making an effort to understand. The implications of Grices Maxims for receivers is included in the next section in the outline of the procedure in step 4 of stage 2 .

Table 2: Maxims

\begin{tabular}{|l|l|}
\hline 1. Quantity & be as informative as required: not more; not less \\
\hline 2. Quality & $\begin{array}{l}\text { do not say what you believe to be false or for which you lack adequate } \\
\text { evidence }\end{array}$ \\
\hline 3. Relevance & say what is congruent with the communication exchange so far \\
\hline 4. Manner & avoid obscurity of expression and ambiguity; be brief and orderly \\
\hline
\end{tabular}

\section{Translation as Reverse Engineering}

\subsection{Phase 1: stages and steps}

The procedure is organised as a sequence of two stages: 1 (with two steps) and 2 (with four steps). Stage 1 relates to the surface information you can see in the text itself. Stage 2 relates to deep information that can only be inferred from the four layers of information concealed in the deeper levels of the text.

What follows in this section are 1. instructions for the use of the procedure - in a sense, the Standard Operating Procedures (SOPs) for Phase 1 of the process - which offer you a set of targeted questions that may help to make the meanings that are implicit in the text explicit and to do so in a structured way and 2. half a dozen short texts from different genres that you might like to analyse (a partial analysis is provided that reflects the interests and competence of the writer of this paper not the answer!) . 
You may find Six Honest Servingmen [18] Kipling, R helpful with its light-hearted listing of the kind of question that might be asked.

\author{
I keep six honest Servingmen; \\ (They taught me all I knew); \\ Their names were What? and Why? and When? \\ And How? and Where? and Who?
}

Try asking yourself questions such as the ones below, attempting to give provisional answers to them and noting linguistic (and other) evidence in support of the analysis at each point as you build a progressively "rich picture" [13] of the meanings suggested to you by the original text.

\title{
Remember
}

1. that you don't have to answer all 23 questions in the six steps. Just select those which you think will be most fruitful as you go along "unpacking" the meanings of the texts,

2. that the layers are not ranked in order of importance or the order in which you should access them. They are just arranged in an order which has often been found to give the quickest access to the deeper levels of the text.

3. that, you have to start with Stage 1 - the physical layout and surface linguistic structure of the text itself - to locate key information and links to the hidden meanings located in its deeper levels

4. that, after studying the text itself at Stage 1, you are absolutely free to start where you like and move back and forth as you wish between layers and between them and the text itself and

5. that you can stop when you feel you have got as much as you want from the text.

\subsection{Questions}

\begin{tabular}{|c|c|c|}
\hline \multicolumn{2}{|c|}{ Stages and steps } & \multirow{2}{*}{\begin{tabular}{|l} 
Deconstruction \\
he Textual Interface and note immediately observable facts.
\end{tabular}} \\
\hline 1. & Access the Textual Interface and note immediately observable facts. & \\
\hline 1.1 . & \multicolumn{2}{|r|}{$\begin{array}{l}\text { How is the text presented? } 1 \text {. What language and/or non-language symbols/images/icons are } \\
\text { used? 2. How many letters, syllables, words, clauses, sentences (totals) are there? } 3 \text {. } \\
\text { Same/different font sizes, } 4 \text {. What pitch and case, are used? } 5 \text {. What colour are the letters and/or } \\
\text { symbols and } 6 \text {. the background? } 7 \text {. What is the arrangement of lines, rhymes etc... and } 8 \text {. what } \\
\text { language(s) is/are used? }\end{array}$} \\
\hline 1.2 & \multicolumn{2}{|r|}{$\begin{array}{l}\text { What is the lexico-grammatical structure of the text? 1. Is the lexis common or rare, } 2 \text {. the syntax } \\
\text { complex or simple? 3. Are the collocations between nouns and their modifiers (or qualifiers) } \\
\text { marked or unmarked? and } 4 \text {. Is the ordering of elements in the structure of phrases marked or } \\
\text { unmarked? }\end{array}$} \\
\hline 2 & \multicolumn{2}{|r|}{$\begin{array}{l}\text { Analyse each of the four layers below recursively, iteratively, and in any order, inferring } \\
\text { meanings that are signalled by the text, continually checking with it, and building up a } \\
\text { progressively sophisticated picture of the many meanings implicit in it. }\end{array}$} \\
\hline
\end{tabular}




\begin{tabular}{|l|l|}
\hline 2.1 & Intertextual layer: What kind of text does this resemble? \\
\hline 2.2 & $\begin{array}{l}\text { Intentional layer: } 1 . \text { Why did the writer write this text. 2. What effect did (s)he intend to have on } \\
\text { the reader? }\end{array}$ \\
\hline 2.3 & $\begin{array}{l}\text { Contextual layer: } 1 \text {. Who wrote this text and 2. Who the intended reader(s)? 3. When and 4. was } \\
\text { it written? }\end{array}$ \\
\hline 2.4 & $\begin{array}{l}\text { Cultural layer: What characteristics of the text locate it in a particular culture? 1. Can you } \\
\text { identify Lexical and/or Syntactic, and/or Semantic choices in the text that signal social } \\
\text { relationships between participants, such as degrees of formality and politeness? 2. Are there } \\
\text { literary and/or topical allusions and/or signs of irony or humour...? 3. Is there evidence of the } \\
\text { writer being faithful to the Co-operative Principle and/or flouting its maxims in some way? }\end{array}$ \\
\hline
\end{tabular}

\subsection{Example texts: comments and partial analysis}

The six texts below begin with two texts (A and B) whose arrangement emphasises the content of the message and move on to one whose archaic language triggers memories of older forms of English poetry (Text C). Next comes the transcript of part of a relaxed conversation (Text D), whose text type and intention are unambiguously clear but radically alters when the continuation of the comment is added to it. The series ends with two humorous cartoons: Text $\mathrm{E}$, where the surface meaning of the cartoon that is obvious but only access to the cultural layer allows the reader to recognise that the joke hinges on a pun and Text F, where the humour also depends on cultural knowledge, specifically, the flouting of several maxims the Co-operative Principle.

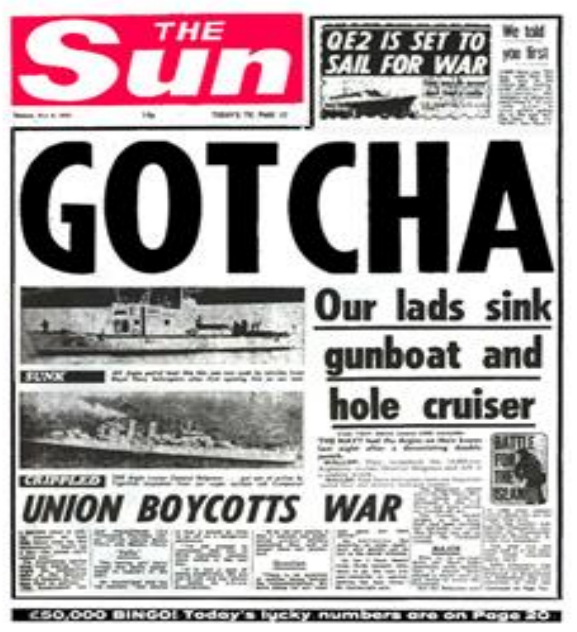




\begin{tabular}{|l|l|l|}
\hline Stage 1 \& Links: presentation & \multicolumn{2}{|c|}{ LAYERS } \\
\hline $\begin{array}{l}\text { Pictures of sinking ships + a single, } \\
\text { huge bold, six-letter word in upper } \\
\text { case takes up a good third of the page. }\end{array}$ & Intertextual & Front page of newspaper \\
$\begin{array}{l}\text { Seven word sub headline in smaller } \\
\text { font and underlined }\end{array}$ & $\begin{array}{l}\text { Intional encourage the "war effort" } \\
\text { Actual effect: the whole range of individual } \\
\text { responses from 100\% approval to 100\% disapproval } \\
\text { (see analysis in } \\
\text { https://www.theguardian.com/business/2002/apr/07/ } \\
\text { pressandpublishing.media } \\
\text { downloaded 19th July 2020. }\end{array}$ \\
$\begin{array}{l}\text { Introductory sentence: "THE NAVY } \\
\text { had the ARGIES on their knees last } \\
\text { night after a devastating double } \\
\text { punch" }\end{array}$ & Contextual \\
$\begin{array}{l}\text { Two stories, each with same small } \\
\text { upper case headline and lower case } \\
\text { font. }\end{array}$ & $\begin{array}{l}\text { Sinking of Argentinian cruiser "Belgrano" on 2 } \\
\text { May 1982 during Falklands War } \\
\text { Writer: journalist } \\
\text { Readers: right-leaning British groups }\end{array}$ \\
$\begin{array}{l}\text { Syntax: simple e.g "Our lands sink } \\
\text { gunboat and hole cruiser }\end{array}$ & Cultural \\
$\begin{array}{l}\text { Lexis: common but often negatively } \\
\text { and positively emotive e.g. "Gotcha", } \\
\text { "Argies", "on their knees", } \\
\text { "devastating double punch", } \\
\text { "WALLOP", "useless wreck" versus } \\
\text { "our lads", "THE NAVY", "Task } \\
\begin{array}{l}\text { Force". } \\
\hline\end{array}\end{array}$ & \\
\hline
\end{tabular}




\title{
Text B
}

\author{
If the world were \\ a global village of 100 people, \\ 70 of them would be unable to read, \\ and only 1 of them would have a college \\ education. Over 50 would be suffering from \\ malnutrition, and over 80 would live in what we call \\ sub-standard housing. If the world were a global village \\ of 100 residents, 6 of them would be Americans. These 6 \\ would have half of the village's entire income; the other 94 \\ would exist on the other half. How would the wealthy \\ 6 live "in peace" with their neighbors? Surely they \\ would be driven to arm themselves against the \\ other 94 ... perhaps even to spend, as we do, \\ more per person on military defence \\ than the total per person \\ income of the others.
}

\begin{tabular}{|c|c|c|}
\hline Stage $1 \&$ Links: presentation & & LAYERS \\
\hline $\begin{array}{l}\text { Seven sentences with a total of } 125 \\
\text { words ( } 2818169911 \text { and } 34 \text {, } \\
\text { respectively) presented in the form of } \\
\text { a circle } \\
\text { Lexis: common. } \\
\text { Syntax: simple. } \\
\text { Americanisms \& references: e.g. } \\
\text { "neighbors" and "Americans... as we } \\
\text { do" }\end{array}$ & $\begin{array}{l}\text { Intertextual } \\
\text { Intentional } \\
\text { Contextual } \\
\text { Cultural }\end{array}$ & $\begin{array}{l}\text { Part of a newspaper/journal article/internet posting } \\
\text { To persuade. } \\
\text { Changed attitudes to inequality? } \\
\text { Contemporary. } \\
\text { American writer \& readers } \\
\text { Ongoing debate on inequality }\end{array}$ \\
\hline
\end{tabular}




\section{Text C}

Who so beset him round

With dismal Storys,

Do but themselves Confound;

His Strength the more is.

No Lyon can him fright,

He'l with a Gyant Fight,

But he will have a right,

To be a Pilgrim.

\begin{tabular}{|l|l|l|}
\hline Stage 1 \& Links: presentation & \multicolumn{2}{|c|}{ LAYERS } \\
\hline Lines: 8 & Intertextual & Poem/Hymn \\
Syllables: 6, 5, 6, 5, 6, 6,6,5 & Intentional & $\begin{array}{l}\text { To justify Christian faith } \\
\text { Rhyme: ab ab. }\end{array}$ \\
$\begin{array}{l}\text { Lexis: some archaic e.g. "beset him } \\
\text { round" }\end{array}$ & & Clerease Christian faith \\
$\begin{array}{l}\text { Spelling: "avow'd", "He'l" "Storys", } \\
\text { "Lyon","Gyant" }\end{array}$ & Contextual & $\begin{array}{l}\text { Clergyman? Christian readers. England? Not } \\
\text { contemporary }\end{array}$ \\
$\begin{array}{l}\text { Capitalisation: "Pilgrim"," Storys", } \\
\text { "Confound", "Strength", "Lyon", }\end{array}$ & Cultural & Christian theology \\
"Gyant", "Fight" & \\
Syntax: complex e.g. & \\
"Who so beset him round... & \\
Storys, Do but themselves Confound; & \\
His Strength the more is. & \\
No Lyon can him fright, & \\
He'l with a Gyant Fight" & \\
\hline
\end{tabular}

Text D

"I've never met a woman who could drive."

\begin{tabular}{|l|l|l|}
\hline Stage 1 \& Links: presentation & \multicolumn{2}{|c|}{ LAYERS } \\
\hline Lines: 1 & Intertextual & Conversational comment. \\
Words: 8 & Intentional & To assert \\
Lexis: common & & To consider \\
Syntax: simple & Contextual & man, pub with (male) friends contemporary UK \\
& Cultural & Misogynistic insult to women \\
& &
\end{tabular}

6 The speaker continued "Putt yes. But not drive" = BI "Pat, ya tetapi tidak bisa mengemudi". This significantly changes the meaning of the text to: Context: Golf club Pro at club bar with student player(s), Culture: relaxed neutral professional discussion, Intertext: coaching, Intention to instruct player(s) on how to improve driving 


\section{Text E}

\section{The Tooth Ferry}

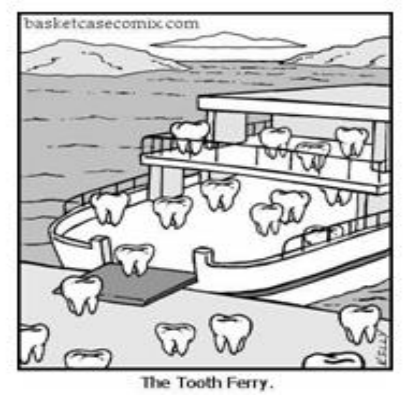

\begin{tabular}{|l|l|l|}
\hline Stage 1 \& Links: presentation & \multicolumn{2}{|c|}{ LAYERS } \\
\hline Picture + title + internet link & Intertextual & Cartoon \\
Lines: 2 & Intentional & To amuse \\
Words: 5 & & To be amused \\
Lexis: common & & Internet posting by basketcasecomix.com \\
Syntax: simple & Contextual & Pun on "Tooth Fairy"' \\
& Cultural & Pun \\
& & \\
\hline
\end{tabular}

7 If a child loses a milk tooth and puts it under the pillow at night, the Tooth Fairy will come and replace it with a small amount of money. 
Text F

Frieda
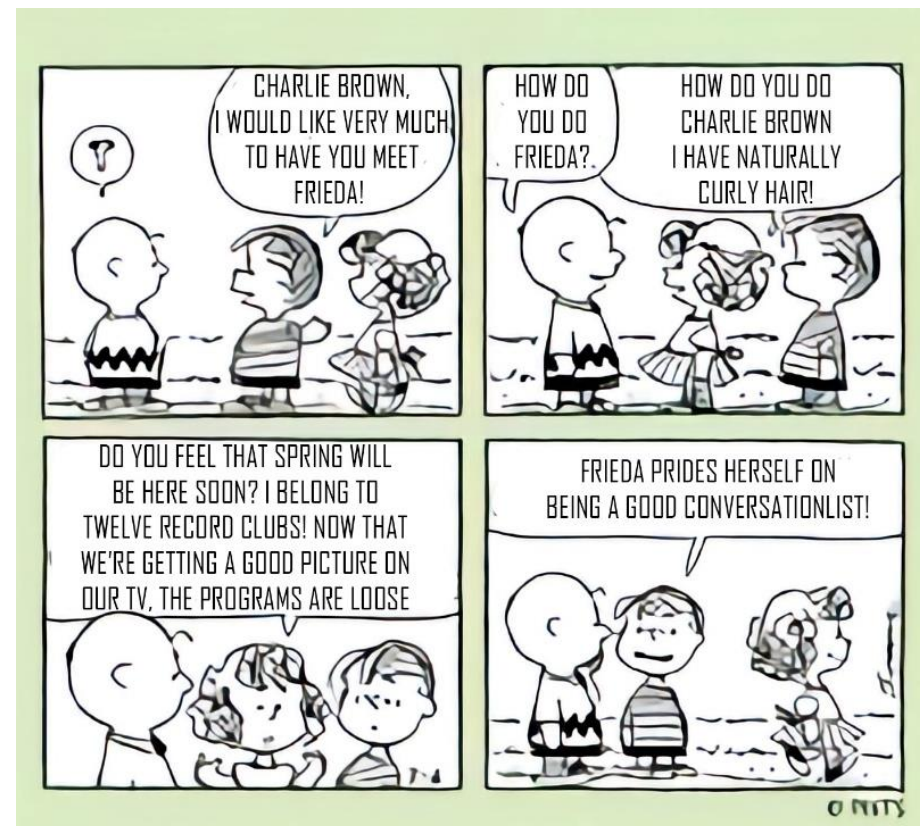

\begin{tabular}{|c|c|c|}
\hline Stage 1 \& Links: presentation & & LAYERS \\
\hline $\begin{array}{l}\text { Participants: } 3 \text { children } \\
\text { Exchanges: } 6 \text { ( } 1 \text { non-verbal: question } \\
\text { mark) } \\
\text { Words: } 0,12,5,6+5,9+21,8 \\
\text { Lexis: common } \\
\text { Syntax: simple but incoherent. Begins } \\
\text { normally with ritual introduction } \\
\text { exchange but although each of } \\
\text { Frieda's responses are unremarkable, } \\
\text { taken } \\
\text { together they are unco-ordinated: } \\
\text { flouting three of the four Co-operative } \\
\text { Principle's Maxims: Quantity, } \\
\text { Relevance, and Manner. } \\
\text { It is unclear whether Linus' final } \\
\text { comment is intended to be taken } \\
\text { literally or whether it is an intentional, } \\
\text { humorous flouting of the first element } \\
\text { of the Maxim of Manner (ambiguity) } \\
\text { counting as irony. }\end{array}$ & $\begin{array}{l}\text { Intertextual } \\
\text { Intentional } \\
\text { Contextual } \\
\text { Cultural }\end{array}$ & $\begin{array}{l}\text { Cartoon. } \\
\text { To entertain. } \\
\text { Newspaper/magazine... } \\
\text { Famous cartoon series. Three participants: Linus, } \\
\text { Charlie Brown and Frieda. } \\
\text { Setting: Frieda is introduced to Charlie Brown by } \\
\text { Linus. }\end{array}$ \\
\hline
\end{tabular}




\section{Conclusion}

Since a good number of abstract ideas and practical techniques that would normally call for presentation, explanation and practice over several intensive weekend workshops have been crammed into the straitjacket of less than 5000 words, I fear, that I have probably more than once inadvertently flouted one or more of Grice's Maxims, especially Quantity and Manner.

If so, I must apologise for the hard work I have forced upon readers but hope, nonetheless, that whatever they have been able to discover in my text had the effect of triggering new ideas in their imaginations that will encourage them to look further into the issues that have been discussed and to try to apply the techniques of Translation as Reverse Engineering in their own practice as readers, especially as a preparation for discussion and/or translation.

We can not do better, I think, than the end this paper by pondering the assertion made by [19] de Beaugrande, R 1978 about the importance of competent reading in relation to translation

Only if the reading process is consistently pursued to the point where the interpretation is maximally dominated by text-supplied information can a truly objective translation be produced, that is, a translation which validly represents the perceptual potential of the original (original emphasis).

\section{References}

[1] Steiner G. After Babel: aspects of language and translation. Assen: van Gorcum; 1975 p. 45

[2] Jakobson R. Closing statement: linguistics and poetics. In Sebeok, TA, editor. Style in language.

Cambridge, Massachusetts: MIT; 1960. p. 159

[3] Seton.co.uk The History of Safety Signs 18 May 2017

https://www.seton.co.uk/legislationwatch

/article/the-history-of-safety-signs/ downloaded 15.July 2020

[4] Brown G, Yule G. Discourse Analysis. Harlow: Longman. p 67.

[5] Bell RT. Translation and Translating: Theory and Practice. Harlow, Essex: Longman;

1991. p.298

[5] Bell RT 254-56

[6] Diekman, JR. Get your message across" how to improve communication New York: Prentice

Hall 1979

[7] Sayers Peden, M. Building a translation, the reconstruction business: poem 145 of Sor Juana

Iñes de la Cruz. In Biguenet, J and Schulte, R editors. The Craft of Translation Chicago: University of Chicago 1989

[8] Darwish, A. 2008. Optimality in translation Melbourne: Writescope Pty Ltd 2008: p. 162-164

[9] Lawlor, Leonard, "Jacques Derrida", The Stanford Encyclopedia of Philosophy (Fall 2019 
Edition), Edward N. Zalta (ed.), URL = $<$ https://plato.stanford.edu/archives/fall2019/entries/ derrida/>.]

[10] Fairclough, NL. Critical discourse analysis. The critical study of language. London and New York:

Longman 1995 p. 265[

[11] https://canvas.instructure.com/ courses/838884/

pages/unit-3-lesson-6-reverse-engineering downloaded 15th July 2020

[12] Searle, J. Speech Acts London: Cambridge University Press 1969 p 56

[13] Checkland, P. Systems Thinking, Systems Practice Chichester: John Wiley \& Sons. 1999.page 317

[14] Baker, M. editor Routledge encyclopedia of translation studies. London. Routledge 1998 103

[15] Littlejohn, A. Johannes Gutenberg and the Printing Press: Social \& Cultural Impact https:/owlcation.com/humanities/Johannes-Gutenberg-and-the-Printing-Press-Revolutio

downloaded 18th July 2020

[16] Trompenaars, F. and Hampden-Turner, C. Riding the waves of culture: understanding cultural diversity in business London: Nicholas Brealey Publishing Ltd. Trompenaars and Hampden-Turner 2001.87

[17] Grice, H. Logic and conversation. In Cole, P and Morgan, JL editors. 1975 Syntax and semantics.

vol 3: Speech Acts. London; Academic Press.1975. p. 41-58

[18] Kipling, R. The Elephant's Child. San Diego, CA; Harcourt. 1988. p. 48

[19] de Beaugrande, R. Factors in a theory of poetic translating. Assen: van Gorcum; 1978 p. 88 